\title{
Conceptual design of kenaf fiber polymer composite automotive parking brake lever using integrated TRIZ-Morphological Chart-Analytic Hierarchy Process method
}

\begin{abstract}
This paper presents the conceptual design of kenaf fiber polymer composites automotive parking brake lever using the integration of Theory of Inventive Problem Solving (TRIZ), morphological chart and Analytic Hierarchy Process (AHP) methods. The aim is to generate and select the best concept design of the component based on the product design specifications with special attention to incorporate the use of natural fiber polymer composites into the component design. In this paper, the TRIZ contradiction matrix and 40 inventive principles solution tools were applied in the early solution generation stage. The principle solution parameters for the specific design characteristics were later refined in details using the aid of morphological chart to systematically develop conceptual designs for the component. Five (5) innovative design concepts of the component were produced and AHP method was finally utilized to perform the multi-criteria decision making process of selecting the best concept design for the polymer composite automotive parking brake lever component.
\end{abstract}

Keyword: Analytic hierarchy process; Composite materials; Conceptual design; Hierarchical systems; Kenaf fibers; Polymers; Product design 